\title{
Study on the Application of Traditional Patterns Elements of Oroqen in Amur River Basin in Modern Ceramic Design*
}

\author{
Tianbao Yan \\ College of Fine Art and Design \\ Heihe University \\ Heihe, China
}

\author{
Yuyun Wang \\ College of Fine Art and Design \\ Heihe University \\ Heihe, China
}

\begin{abstract}
With the development of the times and social economy, the traditional ethnic culture of Oroqen has been gradually assimilated and its regional characteristics have gradually subsided. In the field of ceramic design in China, there has also been a phenomenon of uniformity and lack of national characteristics. Therefore, how to rationally develop and utilize rich ethnic cultural resources, protect national cultural heritage, inherit and carry forward the ethnic characteristics of the Oroqen nationality, realize dynamic protection, and adapt to social development are important issues facing the design world today. This paper takes modern ceramic design as the research background, and takes the Oroqen traditional pattern as the research object, and analyzes how to apply the Oroqen traditional pattern to ceramic design. By studying the modeling patterns, composition patterns, formal aesthetics and design thinking of the Oroqen traditional patterns, the author puts forward the idea and method of dynamic protection of its cultural heritage, and tries to play a positive role in the inheritance and protection of the Oroqen culture.
\end{abstract}

Keywords-the Oroqen nationality; traditional pattern; modern ceramic design

\section{INTRODUCTION}

The Oroqen people have created a rich and colorful spiritual culture in the long-term hunting production and social practice. The literature of the Oroqen nationality is mainly oral creation, which has been passed down from generation to generation through word. There are mainly myths, songs, proverbs, stories, and so on. The handicrafts that the Oroqen people are best at are boxes, urns, barrels, boxes and light birch boats made from a large number of birch-bark. A variety of beautiful patterns carved on the above fully reflecting the traditional characteristics of their hunting culture.

The traditional patterns of the Oroqen are divided into beliefs, houses, costumes, utensils, and art. The Oroqen people have lived a long hunting life, so their traditional patterns are relatively primitive. Due to economic constraints,

*Fund: School of Fine Art and Design of Heihe University key project "Study on the Application of Traditional pattern Elements of Oroqen in Modern Ceramic Design” YSZ201901. it is impossible to create gorgeous and expensive materials for the works they create. They make full use of the surrounding natural environment to find the most economical and convenient materials for processing. These materials are inexpensive and have a rough texture, resulting in natural morphological features such as texture, texture, and luster. Therefore, their art is rough, simple, and wild. In the process of creation, these folk artists have greater freedom, and often produce flashing things in improvisational production. With their observations of nature, they express nature in its simplest form as they please. The figure patterns are mostly front, and the animal patterns are mostly side-mounted with simple and perfect shape. This method is a common method used by Chinese folk artists, called the "image shape" method. In the plant-shaped decorative patterns, there are few realistic works, and most of the patterns appear in an abstract form. Most of these abstract patterns are organized in harmonious lines; some are contrasted with color blocks, complement each other and match each other.

The Oroqen pattern is also a relatively primitive type of pattern, which embodies the intertexture and integration of utility functions and aesthetic consciousness. It can be seen from the Oroqen products that most of them are for practical use. The continuous improvement of the process based on practical purposes makes them both practical and aesthetic. Before the liberation, the life of the Oroqen people was basically intertwined with material activities and spiritual activities, and their material products and spiritual products were integrated. But there are also some products that are purely spiritual, such as the statue of gods carved and drawn for sacrifice.

The study of the Oroqen traditional patterns is not to cherish the memory of yesterday but to look forward to tomorrow. On the one hand, because China's design is taking the road of "internationalization", we must find and create a modern design culture that belongs to our own nation according to the tradition of our nation. This is an important way to truly move toward "internationalization". On the other hand, the Oroqen culture is in a state of impending loss, so the protection and inheritance of traditional culture and traditional patterns has reached an urgent point. This is the significance of our study of the Oroqen traditional patterns. 
Its past is a precious national art heritage. Now it is an artistic embodiment of the colorful mass life and a living tradition of national art, so it is an important part of the Chinese national culture.

\section{THE REFERENCE OF OROQEN TRADITIONAL PATTERN ELEMENTS IN MODERN CERAMIC ART}

The pattern forms a multi-element combination to form a planar design pattern of this new form. These patterns include individual patterns, corner patterns, suitable patterns, and two-sided continuous patterns. In the process of the changes in the patterns and the use of patterns of the Oroqen nationality, certain patterns have produced different meanings. The law of change comes from the natural living environment, and people also give the aesthetic meaning of patterns. Through the graphic art, the expression and communication of emotions are reproduced through various means, so that they rise to the art form and feedback to all aspects of life. From simple individual patterns to complex suitable changes, individual forms to rich combinations, and the influence of foreign cultures, the pattern arts of the Oroqen people have been continuously developed, forming a rich pattern style which to be inherited.

The Oroqen people use the art of ornamentation extensively. In the practice of life, as time goes by, the natural simple ornamentation gradually changes into a complex one with certain artistic connotation, thus forming the unique artistic pattern of the nation. These patterns of art go from simple to complex, from a single independent natural form to a suitable pattern with rich combination, which is a gradual development process. The beautiful nature endows people with endless imagination, which makes the Oroqen people create brilliant and beautiful pattern art and apply it to all aspects of life. The art of this hunting nation's ornamentation, through various patterns, is widely used on birch bark boxes, on the curtains, and on various beddings, but most of them are applied to the decoration of costume patterns. The patterns are diverse, the combinations are colorful, and the techniques of expression are endless. The ethnic pattern art of the Oroqen nationality is widely circulated among the people.

\section{A. Principles of Application of Oroqen Traditional Graphics in Ceramic Design}

1) The principle of embodying the traditional cultural connotation of the nation: In the contemporary design works, embodying the national traditional cultural connotation, infiltrating the national feelings and national spirit is the need of modern cultural communication. Integrating traditional patterns into ceramic design will become an important content of our modern people's cultural life. The application of Oroqen traditional patterns to ceramic design adds color to modern people's life. It also enables modern people to learn more about this minority and inherit and protect the cultural heritage of Oroqen.

In international exchanges, the introduction of designs with ethnic characteristics is an important task for designers in the new era. Being able to spread and develop the traditional national cultural connotations will bring infinite design inspiration to modern designers. Based on national culture, but not limited to form, to macroscopically embody the witty, simple and brave spirit of the Oroqen is the highest realm pursued by designers.

2) The principle of inheritance and innovation of traditional patterns: The traditional patterns of the Oroqen nationality began to be created with the emergence of the nation, and gradually formed through historical accumulation and sublimation. It comes from the life of Oroqen people, which a social, holistic, typed cultural foundation and eternal motivation, and its unique artistic value affects people's lives at all times.

The traditional patterns of the Oroqen nationality are diverse in form and rich in style. These traditional patterns formed in the past thousands of years can best reflect the cultural thinking and design ideas of the nation. In the field of modern ceramic design, we are not worried about the technical capabilities of Chinese designers, but their inferiority and loss in thoughts and beliefs, that is, the existence of a basic quality and humanistic spirit, and whether they still have a culture conscious ability. Nowadays, many famous Chinese designers and some internationally renowned and outstanding design works have performed well. It is equally important to inherit traditions and innovate based on traditions in design.

\section{B. Application Strategy of Oroqen Traditional Patterns in Ceramic Design}

\section{1) Application strategy of design based on traditional cultural connotation}

a) Application strategy of design based on unique cultural connotation: The hunting culture of the Oroqen nationality vividly describes the characteristics of the Oroqen culture and expresses the unique national cultural connotation of the Oroqen. The hunting-based production mode determines that they eat animal meat and wear animal skins all year round. The production and living tools they use are mainly spears, bows and arrows, birchbark boats, snowboards, hounds, reindeer, etc., all made of birch bark or leather; They believe in shamanism, and the expressions of religion are nature worship (the sun god, the moon god), totem worship (tiger, bear) and ancestor worship (the ancestral gods enshrined as "Ajiao Rubo Rukan"); They create literature, folk songs, Mosukun dances, stories, myths and legends around the production and lifestyle of hunting and gathering.

b) Application strategy of design based on the authenticity cultural connotation: The Oroqen national culture has the authenticity cultural connotation. It carries the long-distance natural and historical culture, and contains the respect for the natural environment and the thoughts of protecting the original ecology, in order to coexist harmoniously with nature. It also reflects the courage and rough and simple national character of the Oroqen ancestors in the primitive natural environment, and fully demonstrates the living state of the nation in the most primitive natural 
environment. The living environment of the Oroqen nationality preserves the original settlement lifestyle. With the acceleration of economic development, the original ecological characteristics of the Oroqen nationality are fading away with the gradual replacement of the modern life. The changes in economic form and cultural form have forced the "original ecology" of national culture to gradually disappear, and we have to face the reality that they will eventually become a legacy. If we deviate from the principle of authenticity, it will have a negative impact on the direction of inheritance and protection of the intangible cultural heritage.

c) Application strategy of design based on regional cultural connotation: Different geographical locations, natural environments, production modes, lifestyles, social structures, ideologies, and the development of aesthetic concepts have determined the unique cultural characteristics of their different ideologies. Different regional characteristics form different cultural ideologies. They reflect the results of the inevitability and contingency of the development situation of natural laws. They are an indispensable part in the national history, the foundation for the advancement of national culture, and also the soil for the development of national history and culture.

The Oroqen nationality carries a long history of nature and culture. They live in the vast mountainous areas covered by forests and obtain rich material resources from nature. Just as what the "Elunchun Melody", an Oroqen folk song, sang, "The high Xing'an Mountain range has a large forest. The forest is home to the brave Oroqen people. A hunting horse and a spear can't beat all the wild deer all over the mountains", it reflects the courage and rough and simple national character of the Oroqen ancestors in the primitive natural environment, and fully demonstrates the living state of the nation in the most primitive natural environment. In the design, we must preserve the national characteristics of the Oroqen traditional culture, such as uniqueness, authenticity and regionality, and use them as the design basis.

d) Application strategy of design based on traditional pattern emotionalization: Specific to the application of the Oroqen traditional patterns in modern ceramic design, emotional design refers to the design with an eye of the inner emotional needs of the people, targeting the spiritual level of the audience. Incorporate emotional factors into the design, and convey the emotions to others through the Oroqen specific symbols and semantics, forms or materials, colors and other design elements. Reasonable design enables the audience to enjoy the spiritual pleasure while enjoying the material enjoyment, and to arouse the beautiful emotions in people's hearts, in order to achieve the effect of communication, and finally obtain a fulfilling aesthetic experience and make life full of fun and moving. It attracts consumers through form, material, usage and related background stories, to create a happy emotional character.

\section{Methods for Updatingt the Traditional Patterns of the Oroqen Nationality}

\section{1) The molding principle of updating the Oroqen traditional patterns}

a) Recreating imagination: The re-creation of imagination is a process of creative change that must be experienced in traditional Chinese pattern reproduction, and also a fundamental problem to be solved in realizing traditional pattern re-creation. "Recreating imagination" is to dig deep into the original material and its intrinsic information source, expand the radiation surface of its connotation, and based on this, carry out a new round of imagination, or replace it with existing images, shapes and elements to create a new form. In addition, new creations of existing materials can be made based on the theme of the creation, and the prompts of language and text.

The method of association in the Oroqen traditional art often uses metaphor, metonymy, symbolization and harmony to express connotations. For example, in the national decoration, the Lucky Knot pattern is used to describe the symbol "forever". The method used is to use the "real form" to describe the "virtual form", and to symbolize and metaphorize the abstract concept and the spiritual image with concrete objects. When modern design borrows traditional patterns, it is difficult to carry forward the most classic features of the original shape without understanding the connotation and meaning of the original shape.

b) Secondary abstraction: The secondary abstraction is the starting point for the re-creation of national patterns. Although the traditional decorative patterns are the ones obtained through the processing of changing natural image, many of them are complicated in structure and outdated, which are not in line with the needs of modern aesthetics. Therefore, they cannot be directly used, and must be refined, summarized, and secondary abstracted. "Refining and summarizing" is the most basic form of artistic expression. Its characteristic is to use subtraction, to eliminate complex non-essential parts, to retain and perfect the most typical parts, and on this basis, to do further modification and improvement. After refining and summarizing, the shape of the pattern is concise and clear, and the image features are distinct, which conforms to modern aesthetic standards.

c) Observation and association: The famous art master Picasso once said, "I don't want to explore, just find," which tells the importance of observation. The French sculptor Rodin once said: "The so-called masters are such people, who use their own eyes to see what others have seen, and to discover beauty in something that is commonplace."

The Oroqen traditional art is the artistic source of modern artists and designers. For traditional designers, national traditional art patterns are an inspiration for art creation and can lead to infinite imagination. However, the problem of recreation of national patterns is an arduous and concrete artistic activity. It is necessary to sum up a set of rules and methods of re-creation. 


\section{CONCLUSION}

The Oroqen traditional pattern is an excellent cultural heritage of the fishing and hunting nation, and is an important part of the traditional national culture of China, which has far-reaching significance for the influence of Chinese ceramic art creation. The depth of understanding of traditional culture by ceramic creators determines whether they can create excellent works of art. Only by constantly digging deep into traditional culture and understanding the actual connotation of their spirit can we create unique ceramic works.

\section{REFERENCES}

[1] Wang Duan. Analysis of the Traditional Pattern of the Oroqen Nationality [J]. News Enthusiasts, 2010.05. (in Chinese)

[2] Wu Qiong. Study on the Ornamentation of Birch Bark Utensils of the Oroqen in Inner Mongolia [J]. Art Research, 2008.04. (in Chinese)

[3] Wang Zhong. Modern Ceramic Art Design [M]. Changsha: Hunan People's Publishing House, 2008.08. (in Chinese). 